\title{
MAXIMIZING THE RIGHT RENAL VEIN LENGTH IN LAPAROSCOPIC LIVE DONOR NEPHRECTOMY
}

\author{
ANIBAL W. BRANCO, ALCIDES J. BRANCO FILHO, WILLIAM KONDO, MARCO A. DE \\ GEORGE, RONALDO M. DE CARVALHO, RAFAEL F. MACIEL \\ Department of Urology and General Surgery, Red Cross Hospital, Curitiba, Paraná, Brazil
}

\begin{abstract}
Laparoscopic donor nephrectomy has become the standard of care at increasing numbers of renal transplant programs worldwide. The majority of laparoscopic living donor kidneys are procured from the left side because of the longer renal vein and improved transplantation.

The aim of this article is to report a technique to maximize the right renal vein length by performing a hand-assisted cavotomy.
\end{abstract}

Key words: nephrectomy, laparoscopy, live donors, renal transplant

Int Braz J Urol. 2004; 30: 416-9

\section{INTRODUCTION}

Renal transplant from a live donor is generally the chosen treatment for patients with chronic renal failure. In the past, live donor nephrectomy required an open flank incision that resulted in significant postoperative morbidity with prolonged hospital stay and convalescence (1).

Since its introduction in 1995, the laparoscopic approach to live donor nephrectomy has been shown to decrease postoperative pain and hospital stay, reduce blood loss and improve cosmesis while hastening return to normal activity among donors (1-3).

Laparoscopic donor nephrectomy is being progressively accepted with considerably decreased morbidity and favorable graft function. Controversy persists about whether procurement of the right kidney can be done successfully by the laparoscopic approach (4). To date, most laparoscopic live donor nephrectomies have been performed on the left side because the shorter length of the right renal vein poses technical challenges for the transplant surgeon in implanting the kidney into the recipient $(1,3)$.
Right-sided operation is technically more difficult and much more challenging because retraction of the liver is usually required and because the shorter right renal vein increases the risk of allograft thrombosis (5). Nevertheless, some authors prefer rightsided donor nephrectomy because of the lack of renal vein tributaries (4).

We report a hand-assisted technique to maximize the right vein tissue.

\section{SURGICAL TECHNIQUE}

S.V., a 49-year-old non-related male donor, was submitted to preoperative standard immunologic and medical evaluation to confirm his suitability for kidney donation. The requested exams to delineate renal vascular anatomy preoperatively were digital angiography and intravenous pyelogram.

The patient was placed in the $45^{\circ}$ left lateral decubitus position under general anesthesia. The Lap Disc ${ }^{\circledR}$ device (Ethicon Endo-Surgery, Cincinnati, Ohio, USA) was placed in the right lower quadrant through a 8-centimeter skin incision. The abdominal cavity was carefully inspected and a wet surgical towel 
was placed to mobilize the colon and to help in any kind of bleeding. After reflecting the colon, the ureter was identified, isolated with a Penrose drain, and dissected in superior and inferior direction up to the crossing of the iliac vessels, taking care of the tissue between the lower pole and the ureter, leaving it intact to prevent devascularization of the ureter. The abdomen was inflated with carbon dioxide to an intra-abdominal pressure of $14 \mathrm{mmHg}$.

A $10 \mathrm{~mm}$ trocar was placed in the periumbilical area for the 30-degree laparoscope; 2 additional $10 \mathrm{~mm}$ trocars were placed, one approximately halfway between the xiphoid and the umbilicus, and the other in the middle axillary line at the umbilical level. A $5 \mathrm{~mm}$ trocar was placed in the right side to retract the liver.

Dissection continued by the lower renal pole, posterior renal portion and superior renal pole. It could be done easier since the intra-abdominal hand facilitated control of the kidney and prevented rotation and potential damage to the renal hilum. The ureter, isolated by the Penrose drain, was dissected in superior direction, keeping the periureteral tissue. The renal vessels were dissected and freed of surrounding tissues, up to the level of the aorta and inferior vena cava, respectively. The patient presented a double renal vein and a single renal artery.

After completely isolating the renal artery and vein, the kidney was retracted laterally with the assistant's hand. The renal artery was clipped using Hem-O-Lock ${ }^{\circledR}$ (Weck Closure System, NC, USA). A Satinsky clamp was introduced into the abdominal cavity through the hand-port incision and the clamp was placed on the inferior vena cava (Figure-1). Renal vessels were divided (Figure-2) and the kidney was removed from the abdominal cavity. This allowed division of the renal vein with a cuff of the vena cava, maximizing the renal vein length. The cavotomy was sutured laparoscopically with 4-0 Prolene (Figure-3) and afterwards the Satinsky clamp was released from the vena cava. No bleeding was detected (Figure-4).

The estimated blood loss was $100 \mathrm{~mL}$, the operative time was 90 minutes and the warm ischemia time was 2.5 minutes. The donor had an uneventful postoperative course and was discharged in the second postoperative day.

\section{COMMENTS}

Since the first laparoscopic live donor nephrectomy, it has been shown that this minimally invasive procedure is associated with less blood loss, decreased narcotic requirement, a shorter hospital stay, and an earlier return to normal activity than open donor nephrectomy (1).

Despite the significant experience with laparoscopic donor nephrectomy, the majority of donor nephrectomies are performed on the left side, which is preferred because of the longer renal vein and the greater technical ease of transplantation.

Mandal et al. (5) reported a significant rate (37.5\%) of graft loss in their early experience with eight right kidneys. These losses were attributable to thromboses, postulated to be from the short, thin-walled renal vein. Indeed, concerns about adequate length of the right renal vein have resulted in more than $98 \%$ of laparoscopic donor nephrectomies being performed on the left side (1). In the large series from the University of Maryland, only 29 right kidneys (4\%) were obtained laparoscopically (3). Overall, there is a tendency to avoid the right kidney if the laparoscopic approach is chosen, and some observers have questioned whether we are selecting the proper kidney for donation or are allowing surgical technique to dictate donor criteria (2).

There are conditions for which a right-sided donor nephrectomy is preferred, such as when the left kidney has multiple vessels, duplicated collecting system or other anatomic abnormalities (1).

Obtaining sufficient vascular length with the laparoscopic live donor operation requires attention to several technical details. Adequate mobilization of the liver and judicious blunt retraction with the assistant's right instrument are all that are necessary. In many respects, the right kidney is easier to remove, with less extensive colonic dissection and absence of splenic/pancreatic attachments (2). The dissection of the renal arteries and veins should be complete to their origin at the aorta and to their entrance at the cava, respectively. The typical absence of gonadal, adrenal and lumbar branches makes control of the renal vein more straightforward (2). 


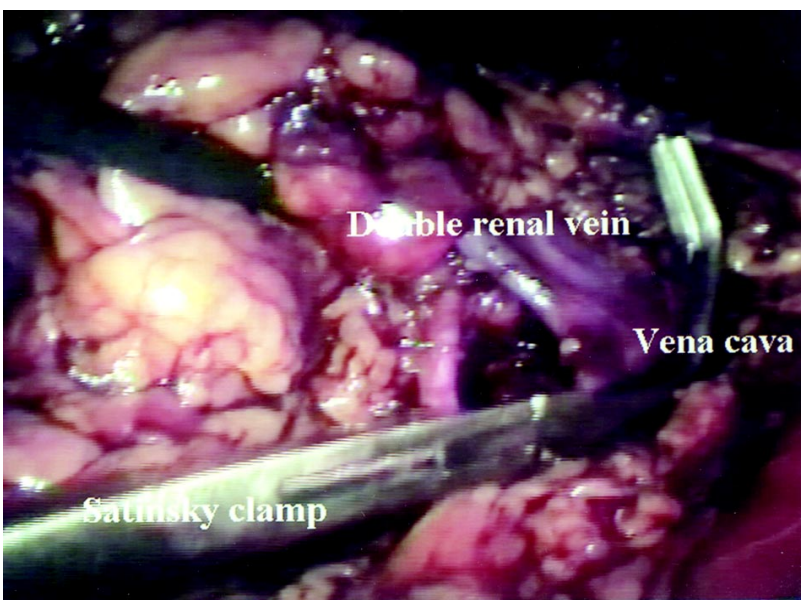

Figure 1 - Placement of the Satinsky clamp on the inferior vena cava.

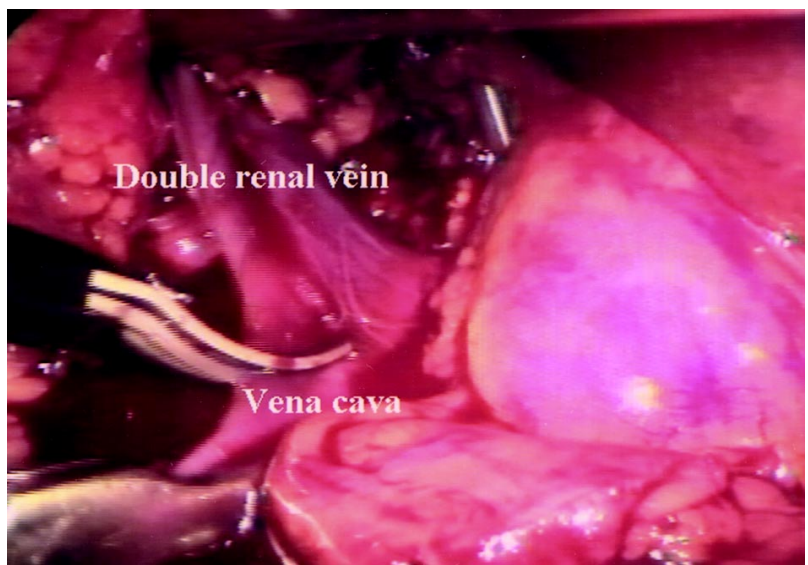

Figure 2 - Cutting the inferior vena cava to maximize the right renal vein length.

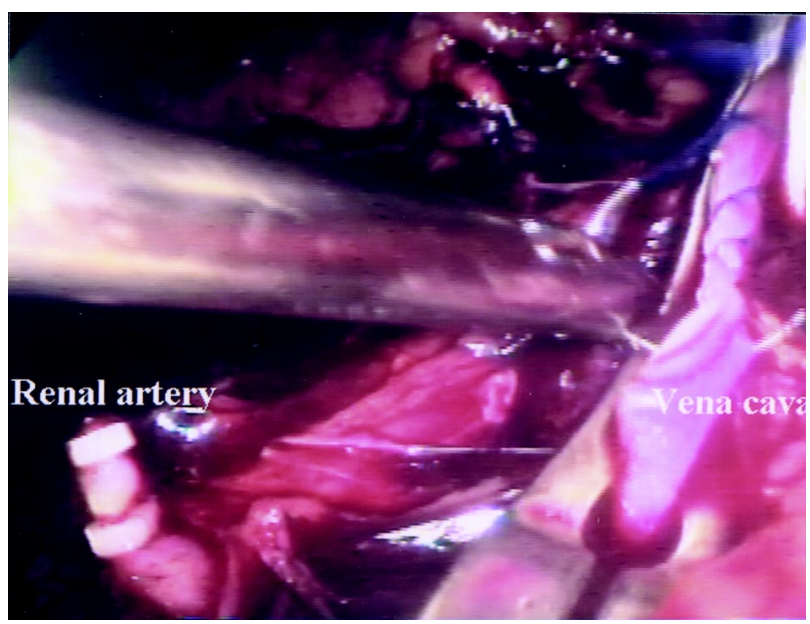

Figure 3 - Laparoscopic continuous running suture using 4-0 prolene.

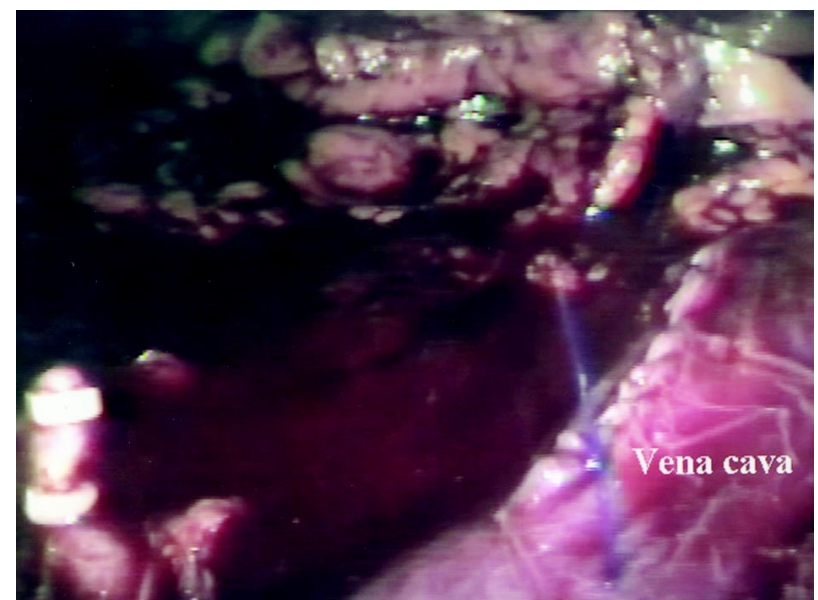

Figure 4 - Final aspect of the inferior vena cava.

The Endo-GIA stapler simultaneously ligates and divides the vessels and is generally reliable; however, misuse and malfunction have been documented and it may lead to bleeding of catastrophic proportions and potentially to donor death (3). Use of this endovascular stapler to divide the right renal vein results in the loss of 1.0 to $1.5 \mathrm{~cm}$ of vein length, what can lead to a more difficult anastomosis in the recipient. Use of Hem-o-Lock clip and Endo-TA stapler maximizes renal artery and vein length, respectively, and is applicable to both left and right kidneys (2). An alternative method to reduce the loss of vascular length is the technique of clamping and cutting the inferior vena cava. A previous described approach to the right-sided kidneys is to perform the complete dissection laparoscopically, including division of the ureter. Then, a small right subcostal margin incision is made and the rectus abdominis muscle is retracted medially.

A side-biting vascular clamp is applied to the inferior vena cava at the origin of the right renal vein. The renal vessels are then divided as in an open procedure and the right renal vein is obtained with a cuff of inferior vena cava. After extraction of the kidney out of the peritoneal cavity, the caval venotomy is closed through the incision with a nonabsorbable, monofilament suture (6). Another reported technique to clamp the inferior vena cava and divide the renal vessels uses a small incision medial to the right anterior superior iliac spine. A modified Satinsky 
atraumatic vascular clamp is inserted into the peritoneum under direct vision and the vena cava is clamped. The renal vein is transected with scissors close to the vena cava and the cavotomy is closed with a laparoscopic running 3-zero polydioxanone suture (7). We also perform the caval suture laparoscopically and we know that loss of control of the vena cava is possible if the clamp is dislodged during organ extraction. A major benefit of the hybrid technique of hand-assisted laparoscopic nephrectomy is the ability to regain rapid vascular control in cases of bleeding. The cavotomy requires suturing, whereas application of the Endo-TA stapler is more rapid and equally secure. However, when experienced laparoscopic surgeons are available, laparoscopic sutures are easily and safely performed, and cavotomy is a good option for maximizing right renal vein length.

\section{REFERENCES}

1. Wang DS, Bird VG, Winfield HN, Rayhill S: Handassisted laparoscopic right donor nephrectomy: surgical technique. J Endourol. 2004; 18: 205-10.
2. Abrahams HM, Meng MV, Freise CE, Stoller ML: Pure laparoscopic right donor nephrectomy: step-by-step approach. J Endourol. 2004; 18: 221-5.

3. Jacobs SC, Cho E, Foster C, Liao P, Bartlett ST: Laparoscopic donor nephrectomy: the University of Maryland 6-year experience. J Urol. 2004; 171: 4751.

4. Lind MY, Hazebroek EJ, Hop WC, Weimar W, Jaap Bonjer H, IJzermans JN: Right-sided laparoscopic livedonor nephrectomy: is reluctance still justified? Transplantation. 2002; 74: 1045-8.

5. Mandal AK, Cohen C, Montgomery RA, Kavoussi LR, Ratner LE: Should the indications for laparascopic live donor nephrectomy of the right kidney be the same as for the open procedure? Anomalous left renal vasculature is not a contraindiction to laparoscopic left donor nephrectomy. Transplantation. 2001; 71: 660-4.

6. Ratner LE, Fabrizio M, Chavin K, Montgomery RA, Mandal AK, Kavoussi LR: Technical considerations in the delivery of the kidney during laparoscopic livedonor nephrectomy. J Am Coll Surg. 1999; 189: 42730.

7. Turk IA, Deger S, Davis JW, Giesing M, Fabrizio MD, Schonberger B, et al: Laparoscopic live donor right nephrectomy: a new technique with preservation of vascular length. J Urol. 2002; 167: 630-3.

Received: July 12, 2004

Accepted after revision: August 13, 2004

Correspondence address:

Dr. Anibal Wood Branco

Rua das Palmeiras, 170 Apto. 201

Curitiba, PR, 80620-210, Brazil

Telephone +55 41 242-6543

E-mail: anibal@awbranco.com.br 